\title{
The Role of Effective Internal Control System to the Financial Management of Hotel Operations
}

\author{
Obinwanne, Cletus Okechukwu* \\ Department of Home Science/ Hospitality Management and Tourism, Michael Okpara University of \\ Agriculture, Umudike, Abia State, Nigeria
}

*Corresponding Author: Obinwanne, Cletus Okechukwu, Department of Home Sciencel Hospitality Management and Tourism, Michael Okpara University of Agriculture, Umudike, Abia State, Nigeria

\begin{abstract}
This study examined the internal control system towards financial management of hotel operations in Aba, Abia State, Nigeria. The researcher employed survey research design and used some selected hotels operating in Aba the commercial nerve center of the State. The population for the study consisted of all the categories of management staff of the selected hotels. The instrument used for the purpose of the study was questionnaire and 60 copies of questionnaire were produced, administered and retrieved. This yielded a response rate of $95 \%$ confidence interval. The questionnaire was designed in six sections in accordance with the research questions and the research hypothesis. The questionnaire was first sent to seven hotel consultants and experts for validation being guided by the research instruments and made necessary corrections. A four point rating scale was used and the mean bench mark of 2.50 was used. The data collected were analyzed using Mean $(X)$ and Standard Deviation (SD). A parametric statistical T-test analysis was used to test the hypothesis. The study revealed strategies used for internal control of the hotel establishments in their operation as triplicate checking system, CCTV, security personnel for monitoring and segregation of duties for the prevention of fraudulent acts. The challenges facing the internal control system of the hotels as shown by the study were inadequate quality of sufficient auditors, negligence, uncertainties, and lack of continuous review of internal control system by financial management. The methods such as checkmating the policies and procedures of internal control, the standard of communication and information of internal control periodic review of performance to budgets and measuring the extent to which goals and objectives are achieved should be adopted by establishments to measure the effectiveness of their various internal controls. Management should engage in periodic departmental transfer of staff to other department of the establishment as being a corrective measure used when fraudulent acts are discovered.
\end{abstract}

Keywords: Internal control system, financial management, hotel operation, establishment, hospitality.

\section{INTRODUCTION}

It is not uncommon to hear cases of misuse of funds, frauds theft or pilferage, loss of assets, mismanagement of organization's vital documents and wrong entering of figures in hotel establishments. This has become a regular occurrence in such establishment where there is no effective internal control system in place. The absence of effective control system in the management of such outfits, no doubt exposes the financial management of the organization and its existence.

For any hotel organization to effectively control its internal operational activities there must be an effective internal control system in place to control materials, machine and money in order to pursue objectives of the organization and meet the interest of all the stakeholders. Internal control system is the whole system of control, both financial and otherwise established by the management policies to secure and safeguard the organizational assets (Chukwu, 2012). Internal control is a process influenced by an entity's board of directors, management, and other personnel designed to provide reasonable assurance regarding the achievement of objectives in the categories of effectiveness and efficiency of operations, reliability of reporting, and compliance with applicable laws and regulations (Norman, 2012). Internal control is defined as a process influenced by an organization's structure, work and authority flows, people and management information systems, designed to help the organization accomplish specific goals or objectives. It is a means by which an organization's resources are directed, monitored, and measured (Anderson, 2008). The essence of establishing an 
effective internal control system in a hotel establishment is to ensure that goals and objectives are achieved in order to be sustained. Organizations will be sustained as long as their goals and objectives are achieved. Control is a measure employed to ensure that goals of organization are reached or attained. Amugo \& Inanga (2009) shows that control activities are the policies and procedures that help ensure management if directives are carried out. They help ensure that necessary actions are taken to address risks to achievement of the entity's objectives. Control activities occur throughout the organization, at all levels, and in all functions.

Internal control system is defined as a method, procedure and arrangement adopted within an organization to ensure accuracy, reliability of the account, safeguard of assets, and complete of recording of accounts (Ackah and Kondegri, 2013). On the other hand, internal control is a process designed to provide reasonable assurance regarding the reliability of financial report and the preparation of financial statements which include policies and procedures that pertain to the maintenance of records that are reasonably detailed, accurately and fairly reflecting the transactions and disposition of the assets of the organization (Drye, Warrenlle, Hedin and Jean, 2004). Because of changing conditions, management needs to determine whether the internal control system continues to be relevant and able to address new risks (Amudo and Inanga, 2009). Hotels are operating in a dynamic environment and are confronted with a lot of uncertainties. The only way to survive in the midst of these uncertainties is to put in place effective internal control system. Those environmental factors that affect the operation of hotels include technological environmental, economic environment, competitive environment, and legal environment. These environmental factors should equally be referred to as risk factors in organizations. According to Amudo and Inanga (2009), every entity faces a variety of risks from external and internal sources that must be assessed. The basic step towards evaluating risks in organizations is to establish well defined objectives that are consistent and connected with each at all levels of the organization. Risk assessment is the identification and analysis of relevant risks to achievement of the objectives, forming a basis for determining how the risks should be managed. Risk assessment is the identification and analysis of those risks associated with the operational achievements, financial reporting, and compliance goals and objectives. Because economics, regulatory and operating conditions will continue to change, mechanisms are needed to identify and deal with the special risks associated with change. Objectives must be established before administrators can identify and take necessary steps to manage risks. Operations objectives relate to effectiveness and efficiency of the operations, including performance and financial goals and safeguarding resources against loss.

The effective internal control system plays the role of providing assurance to financial management of the dependability of the accounting data used in the decision making of hospitality establishments, serving as a tool in checkmating staff and helping financial management to achieve its goal of accountability (Chukwu,2012). According to Sussan and Hatcher (2003), the procedure for internal control in hospitality industry involve the policies and procedures that are in operation to make sure that the management and owners of hospitality establishments take appropriate actions to achieve business objectives. Banta (2013) identified the procedure for internal control system of food and beverage service in hotels sector as triplicate checking system, duplicate checking system, single order sheet, service with order, and computerized checking system (ie electronic cash register and point of sale). True guest (2017) listed 12 bar control standard as follows:

- Position the POS terminal so that customers can see transactions rung up

- Ensure that it is your bar's standard to have alcohol poured first when preparing mixed beverages.

- Require the bartender to give a receipt after each transaction.

- Have the bartender request some sort of payment or tab from each quest immediately after serving drinks.

- Issue POS cards for all your bartenders and servers.

- Security cameras should be installed and facing each register.

- Give each bartender their own separate cash drawers.

- Do not allow the "No sale" button to be used

- Bottle for bottle exchange should be used as your bar's requisition system. 
- The bartender's tip jar should be placed away from the cash register.

- Have a log that is kept at the bar to log any spilled or complimentary drinks given to guests.

- Do not allow unauthorized associates to go behind the bar area.

Concerning the accommodation section which is seen as the major source of revenue in hotel sector as it generates the highest profit among other sections (Drogala, Karaglorgios, Christodoulou and Euaggelidou, 2010). The ways through which internal control is achieve in accommodation section include taking record of rented rooms and the number of people staying overnight; completing correctly and monitoring and confirming invoices for error free; monitoring the book of arrivals and departures; and monitoring the book used for keeping the customer's accounts. Banta (2010) disclosed that effective internal control in accommodation section can be actualized by keeping tracks of sold rooms, generating records used in accounting and bookkeeping and controlling reservation, guest history and gust registration. According to Drogala et al (2010), the control measures for material usage from warehouse in hotels include taking records of invoices and comparing with the actual quantities of the items that exist in the warehouse, taking records of the issued out goods and keeping the safety limit. The capital which is necessary for the smooth running of hotel operations need to be controlled by checking to ensure the investments are always in accordance with the approved investment policy, regular checking of the "Cash point", "deposit" and loans and comparison of investment costs and operating costs (Drogala et al, 2010). The periodic evaluation of the internal control system should be conducted in a regular basis to expose any lapses present to know how strong or weak the system has been.

In measuring whether a particular internal control system is effective (Kansas state university, 2015) referred to five components of internal control system as being the index for the evaluation. The five components must be present and functioning. These five components have been tested and proved to be useful in measuring the effectiveness of internal control system and they are;

i. Control environment: This includes integrity and ethical values, the commitment of competence, leadership philosophy and operating style, the way management assigns authority and responsibility, and organizes and develops its people.

ii. Risk assessment: The process of identifying and analyzing risk is an on-going process and is a critical component of an effective internal control system. Attention must be focused on risks at all levels and necessary actions must be taken to manage it.

iii. Control activities: Control activities include a range of activities as diverse as approvals, authorizations, verifications, reconciliations, review of assets and segregation of duties. Control activities usually involve two elements: A policy establishing what should be done and procedures to implement the policy.

iv. Information and communication: Pertinent information must be identified, captured and communicated in a form and time frame that enables people to carry out their responsibilities.

v. Monitoring: Internal control systems need to be monitored by establishing a process that assesses the quality of the system's performance over time.

According to Norman (2012) an effective system of internal control to be actualized, each of the five components which include control environment, risk assessment, control activities, information and communication and monitoring must be present and operate together in a manner that reduces to an acceptable level the risk of not achieving an objective.

\section{OBJECTIVE OF THE STUDY}

The overall purpose of this study is to examine the internal control system to financial management of hotel operation. A well define organizational structure aids the financial management in executing effective internal control measures. This enhances operational efficiency which is the important feature of internal control system. Specifically, this research work stands to achieve the following objective:

i. Determine the strategies used for the internal control system of the hospitality establishments.

ii. Ascertain the challenges of internal control system facing hospitality establishments. 
iii. Assess methods adopted by hospitality establishments to measure the effectiveness of their internal control system.

iv. Determine the corrective measures used when fraudulent activities are detected.

v. Ascertain the relationship between internal control measures and the operational efficiency of the establishments.

\section{RESEARCH QUESTIONS}

The following research questions guided the researcher to achieve the purpose of this study and they are:

- What are the strategies used for the internal control system of the hospitality establishments?

- Are there really challenges facing the internal control system of hospitality establishments?

- To what extent are the methods adopted by hospitality establishments to measure the effectiveness of their internal control system?

- What are the corrective measures used by the establishment when fraud is discovered?

- To what extent is the relationship between internal control measures and the operational efficiency of the establishments?

\section{RESEARCH HYPOTHESIS}

The hypothesis that guided the researcher in this study was stated below:

H0: There is no significant relationship between the internal control system and operational efficiency of hospitality establishments.

\section{RESEARCH METHOD}

The researcher considered survey research design where some selected hotels operating in Aba Metropolis, the commercial nerve center of Abia State, South Eastern, Nigeria were used. The population for the study consisted of all the categories of management staff of the selected hotels from the top level management to the line supervisors. For this study, the sample size that represented the whole population was determined using Taro Yamane formula for finite population. The "Taro Yamane" formula is as stated below:

$\mathrm{n}=\mathrm{N}$

$$
1+\mathrm{N}(\mathrm{e})^{2}
$$

Where,

$\mathrm{n}=$ Sample size

$\mathrm{N}=$ Finite population

$1=$ Constant

$\mathrm{e}=$ Level of significance taken to be 0.10

$\mathrm{n}=\underline{150}$

$1+150(0.10) 2$

$\mathrm{n}=60$

The instrument used for the purpose of the study was questionnaire and 60 copies of questionnaire were produced, distributed and collected. This yielded a response rate of $95 \%$ confidence interval. The questionnaire has six sections with close-end questions which are in accordance with the research questions and the research hypothesis. The questionnaire was first sent to seven hotel consultants and experts for validation who went through the items, being guided by the research instrument and made necessary suggestions. In the study, questionnaire was constructed using four-point rating scale (Strongly Agree - 4, Agree - 3, Disagree - 2 and Strongly Disagree - 1) with an average mean score of 2.50 as the bench mark for deciding to accept or reject a given item. The data collected were analyzed using Mean (X) and Standard Deviation (SD). A parametric statistical T-test analysis was 
used to test the hypothesis. This was adopted for this research because it shows the relationship between internal control and its role on the financial management of hotels. The mean and standard deviation formulas used were below.

$$
\begin{aligned}
& \mathrm{X}=\sum \frac{(\mathrm{xi}-\mathrm{x})^{2}}{\mathrm{n}} \\
& \mathrm{SD}=\frac{\sqrt{\sum(x i-x)^{2}}}{\mathrm{n}}
\end{aligned}
$$

Where

$\mathrm{X}=$ Mean

$\mathrm{SD}=$ Standard deviation

$\mathrm{xi}=\quad$ The score of the respondent population

$\mathrm{x}=$ Mean score of the respondent population

$\mathrm{n}=$ Number of respondents

The T-test method is stated thus:

tcal $=\frac{X-\mu}{S D / \sqrt{n}}$

Where

$\mathrm{x}=$ Grand mean

$\mu=\quad$ Mean and standard deviation bench mark

$\mathrm{SD}=$ Standard deviation $\quad=\quad$ Number of respondent

\subsection{Decision Criterion for Accepting or Rejecting Research Questions and Hypothesis}

The following decision was applied thus:

Where the mean and standard deviation was not up to 2.5, the analysis and Ho (null hypothesis) was rejected. And if it was up to 2.5 it was accepted, based on mean and standard deviation analysis.

\section{RESULTS AND DISCUSSION}

The results were presented and analyzed using the mean and standard deviation for comparison. The Table 1 shows the data generated in line with responses for items 1 to 4 on the strategies of internal control system used in the various establishments. The result revealed that all the items were accepted by the respondents. The items have a grand mean of 2.92 and the acceptance of the item is based on the fact that each of the items has a mean above 2.5 which is the acceptance bench mark and mean cut off point. Therefore it is crystal clear that the hotels operating within the metropolis employ those strategies of internal control system generally acceptable, known and utilized presently in hotel establishments for profitability and sustainability.

Table1: Strategies used for the internal control system of the hotels

\begin{tabular}{|l|l|l|l|l|}
\hline S/N & ITEMS & $\mathbf{X}$ & SD & DECISION \\
\hline 1 & Use of triplicate checking system & 3.33 & 4.07 & Accepted \\
\hline 2 & Usage of CCTV camera & 3.00 & 3.71 & Accepted \\
\hline 3 & Use of security personnel & 2.33 & 3.52 & Accepted \\
\hline 4 & Segregation of duties & 3.00 & 3.71 & Accepted \\
\hline
\end{tabular}

Source: Field Survey Study, 2017

Grand mean $\mathrm{X}=2.92$, Standard Deviation $\mathrm{SD}=3.75$

The findings revealed that the hotels apply strategies of internal control system which are recommended to be adopted in hospitality establishment. They include the use of triplicate checking system, segregation of duties, CCTV and security personnel. This is in conformity with (Banta, 2013) on his strategies of internal control in regards to triplicate checking system which is good for accurate records for food and beverage sales. The Vanderbilt University (2017) equally had it that segregation of duties among different staff helps in reducing risk of errors and inappropriate actions. Some of the instruments are captured in the appendix of this study. 
Table 2 focuses at the contemporary significant challenges facing internal control system facing the various establishments. The result shows that 1-4 were accepted by the respondents, which indicates that there are contemporary significant challenges facing internal control of the various establishments. The findings in objective two revealed that some of the significant challenges facing internal control system of hotel establishments are the issues of inadequate quality of sufficient auditors, frequently emphasizing on customer's service over internal control system, uncertainties of risk profiling due to the unpredictability of the industry's performance and lack of continuous review internal control system by financial management. According to Mwirigi (2000), these challenges which is in conformity with his study, are capable of running any hospitality outfit down.

Table2: The contemporary significant challenges facing internal control system of hotel establishments

\begin{tabular}{|l|l|l|l|l|}
\hline S/N & ITEMS & X & SD & DECISION \\
\hline 1 & Inadequate quality of sufficient auditors on & 2.50 & 3.48 & Accepted \\
\hline 2 & $\begin{array}{l}\text { Frequently emphasizing on customer's service over } \\
\text { internal control system }\end{array}$ & 3.08 & 3.99 & Accepted \\
\hline 3 & Uncertainties & 3.25 & 4.10 & Accepted \\
\hline 4 & Lack of continuous review of internal control system & 3.25 & 4.46 & Accepted \\
\hline
\end{tabular}

Source: Field Survey Study, 2017

Grand mean $\mathrm{X}=3.02$, Standard deviation $\mathrm{SD}=4.01$

The table 3 looked at the method(s) being adopted by the organization in order to measure the effectiveness of the internal control system. The data shows that 1-4 items were accepted by the respondents. The items have a grand mean of 2.96. The acceptance of the items is as a result of the fact that the items have a mean above 2.5 bench mark. This implies that the organizations have methods that they use as a tool to measure the effectiveness of the internal control.

The findings in objective three revealed the Methods to used by head of departments in order to measure the effectiveness of internal controls. They include: checking on how the policies and procedures of operation in respect to internal control system are carried out, measuring the extent to which goals and objectives are achieved, periodic reviewing of performance to budgets and checkmating the standard of its communication and information.

Table3: Methods used by the hotel organizations to measure the effectiveness of the internal control

\begin{tabular}{|l|l|l|l|l|}
\hline S/N & ITEMS & X & SD & DECISION \\
\hline 1 & Checkmating the policies and procedures of operation & 3.00 & 3.71 & Accepted \\
\hline 2 & Standard of internal control communication and information & 2.83 & 3.40 & Accepted \\
\hline 3 & Periodic review of performance to budget & 2.83 & 3.40 & Accepted \\
\hline 4 & Measuring the extent which goals are achieved & 3.17 & 4.18 & Accepted \\
\hline
\end{tabular}

Source: Field Survey Study, 2017

Grand Mean $X=2.96$, Standard deviation $\mathrm{SD}=3.67$

This is in conformity with Kansas State University (2015) and Norman (2012) that described the five component measures for effectiveness of internal control system which includes control of environment where the head of department establishes a local control environment in order to checkmate how policies and procedures of internal control system are carried out. Communication and information which must be set in a manner that all the personnel will receive a clear message from top management as control system activities relates to the work of others. It is ideal for head of departments to be checkmating how the policies and procedures of internal control operation are carried out. Also it is good to set a standard of communication and information provided for internal control system. Periodic review of performance to budgets and measuring the extent to which goals and objectives are achieved are also good methods to be adopted.

Table 4 revealed the significant corrective measures used by the establishments when fraudulent activities are discovered. The data shows that item 1 to 4 as contained in table 4 were accepted by the respondents which shows that there are corrective measures used when fraudulent activities are discovered. The item has a grand mean above 2.5 bench mark. This implies that there are corrective measures used when fraudulent activities are discovered. 
Table4: The corrective measures used when fraudulent activities are discovered

\begin{tabular}{|c|l|l|l|l|}
\hline S/N & ITEMS & $\mathbf{X}$ & SD & DECISSION \\
\hline 1 & Sacking of staff involved & 2.83 & 4.06 & Accepted \\
\hline 2 & Re-designing the internal control system & 2.83 & 3.40 & Accepted \\
\hline 3 & Periodic inter-departmental changes of staff & 2.67 & 3.31 & Accepted \\
\hline 4 & Paying attention to the internal control system & 3.00 & 4.12 & Accepted \\
\hline
\end{tabular}

Source: Field Survey Study, 2017

Grand mean $\mathrm{X}=2.83$, Standard deviation $=3.72$

The result revealed that corrective measures used when fraudulent activities are discovered in the hotel establishments as sacking staff involved in fraudulent acts, re-designing the internal control system, periodic inter-departmental changes of staff and paying a greater attention to internal control system are all corrective measures used when fraudulent acts are discovered. This is in conformity with Mwirigi (2000) on his study of frequently emphasizing on customer's service over the internal control system and it goes a long way in running the industry down, (Mwirigi, 2000). But paying a greater attention to internal control system can help the industry in safeguarding its assets.

Table5: The significant relationships between the internal control system and operational efficiency of hospitality establishment

\begin{tabular}{|l|l|c|c|l|}
\hline S/N & \multicolumn{1}{|c|}{ ITEMS } & X & SD & \multicolumn{1}{c|}{ DECISION } \\
\hline 1 & Internal control system improves the standard hospitality operations & 2.92 & 3.73 & Accepted \\
\hline 2 & It forces staff to present accurate accounting records of their sales & 3.08 & 3.70 & Accepted \\
\hline 3 & It assures customers to be billed correctly & 3.33 & 3.28 & Accepted \\
\hline 4 & It aids management to reconcile the married checks accurately & 3.33 & 4.07 & Accepted \\
\hline
\end{tabular}

Source: Field Survey Study, 2017

Grand mean $\mathrm{X}=3.17$, Standard deviation $\mathrm{SD}=3.70$

The table 5 looks at the significant relationships between the internal control system and operational efficiency of hospitality establishments. The result showed that the items in the table were accepted by the respondents. The item has a grand mean of 3.17. The acceptance of the item is as a result of the fact that all the items have mean values above 2.5 the acceptance bench mark. This implies that there is a significant relationship between the internal control system and operational efficiency of hospitality establishments.

The findings in objective five revealed that there are significant relationships between internal control system and operational efficiency of hospitality establishments. Which includes: its effort in improving the standard of hospitality operations, its effort in forcing staff to present accurate accounting records of their sales to management, its effort in assuring customers to be billed correctly and its effort in helping management to reconcile the married checks bill and summary sheet with no confusion. Thus, internal control is a process, effected by an entity's board of directors, management and other personnel designed to provide reasonable assurance regarding the achievement of effectiveness and efficiency of operations, reliability of report, compliance with applicable laws and regulation, (Norman, 2010). With this regards, in conformity with the findings, it is crystal clear that internal control system has a deep relationship with operational efficiency. Due to its ability to provide reasonable assurance in order to achieve not only the effectiveness and efficiency of operation, but also to bring about compliance of staff to laws and regulation. According to Banta (2013) on his explanation on triplicate checking system, he stated that before a bill will be issued to a customer or guest, the checks which takes account of orders from a customer which must be seen by the cashier. Therefore, with this regards, internal control system forces staff to present the accurate accounting records of their sales to management. Equally it assures customers to be billed correctly and also helps management to reconcile married checks, bills and summary sheet with no confusion

\subsection{Hypothesis 1: T-Test Analysis}

Table6: Relationship between the internal control system and operational efficiency of hospitality establishment

\begin{tabular}{|l|l|l|l|l|l|l|l|}
\hline Parameter & $\mathbf{X}$ & SD & $\mathbf{N}$ & $\boldsymbol{\mu}$ & Tcal & Tcv & Decision \\
\hline Value & 3.17 & 3.70 & 60 & 2.5 & 1.40 & 1.675 & Reject \\
\hline
\end{tabular}

Source: Field Survey, 2017 
Having rejected the null hypothesis because the bench march is not up to 2.5 , it was concluded that there is significant relationship between internal control system and operational efficiency of hotels establishments. This implies that for any hotel to enjoy operation efficiency there must be an effective internal control system in functional use within the establishments.

\section{CONCLUSION AND RECOMMENDATION}

It is then concluded that good strategies used for internal control of hotel establishments include the use of triplicate checking system for product sales and detection of fraudulent act, CCTV and security personnel for monitoring and segregation of duties for the prevention of fraudulent acts. The challenges facing the internal control of hotel establishments are as a result of inadequate quality of sufficient auditors, negligence, uncertainties, and lack of continuous review of internal control by financial management. The methods such as checkmating the policies and procedures of internal control, the standard of communication and information of internal control, periodic review of performance to budgets and measuring the extent to which goals and objectives are achieved, are good to be adopted by hospitality establishments to measure the effectiveness of their various internal controls. Sacking of staff that are involved in fraudulent act, re-designing internal control system, periodic inter-departmental changes of staff and paying good attention to internal control system are among the good corrective measures used when fraudulent activities are discovered. It was accepted that there are relationships between internal control system and operational efficiency of hotel establishment because internal control system improves the standard of hospitality operations. Management should ensure that there are adequate organizational controls and that each staff knows his duties and equally ensures effective segregation of duties. Management should engage in periodic departmental transfer of staff to other department of the establishment as being a corrective measure used when fraudulent acts are discovered.

\section{REFERENCES}

[1] Ackah,D. kondegri,P.M. (2013). Effectiveness of internal controlsystem as a quality control mechanism in public organizations. Nigeria:Nuel Canti(Nig) publishers.

[2] Amudo, A. and Inanga, E. L. (2009). "Evaluation of Internal Control Systems: A Case Study from Uganda", International Research Journal of Finance and Economics ISSN 1450-2887 Issue 27.

[3] Banta,P. (2013). Food and beverage service. England: Rough Guides.p.62.ISBN 78-1-405-8845-0

[4] Chukwu,P.A.(2012).Impact of internal control system on the financial management of an organization. Enugu: Caritas University press.

[5] Drogalas,G. Karaglorgos,T. Christodoulou,P. and Euaggelidou,A. (2010).Theoretical approach in an internal control system: a conceptual frame work and usability of internal audit in hotel business. Greece: University of Macedonia press.

[6] Drye,K. and Warren, ll p. Ridgway,M. Hedin,B. Jean, G. (2004). Ineffective internal controls: issues of the metropolitan corporate counsel part 11. An article published by version (D) digital version.

[7] Kansas State University (2015). Elements of internal control. England: Manhatton publishing company.

[8] Mwirigi,D. (2000).Challenges of auditing in the hospitality industry.Nigeria: African-Fep publishers.

[9] Norman Marks (2012).How to assess the effectiveness on internal control. USA: Wordpress. company

[10] Susan,C.P. and Hartcher,J. (2003).Benefits of internal control system. Autralia: Wordsworth publishing company.

[11] Trueguest (2012).Basic bar internal control. USA: Word press Company

[12] Vanderbilt University (2017). Different types of internal control. New York: Mc Graw-Hill.

Citation: Obinwanne, Cletus Okechukwu. "The Role of Effective Internal Control System to the Financial Management of Hotel Operations". International Journal of Research in Tourism and Hospitality (IJRTH), vol 5, no. 2, 2019, pp. 17-24. doi: http://dx.doi.org/10.20431/2455-0043.0502003.

Copyright: () 2019 Authors. This is an open-access article distributed under the terms of the Creative Commons Attribution License, which permits unrestricted use, distribution, and reproduction in any medium, provided the original author and source are credited. 